\title{
Startup impurity diagnostics in Wendelstein 7-X stellarator foreseen in the first operational phase
}

\author{
Henning Thomsen ${ }^{*}$ \\ Max-Planck-Institut für Plasmaphysik, \\ Wendelsteinstr. 1, 17491 Greifswald, Germany \\ E-mail: henning.thomseneipp.mpg.de
}

\author{
A. Langenberg ${ }^{1}$, D. Zhang ${ }^{1}$, G. Bertschinger ${ }^{2}$, C. Biedermann ${ }^{1}$, W. Biel ${ }^{2}$, R. \\ Burhenn $^{1}$, B. Buttenschön ${ }^{1}$, K. Grosser ${ }^{1}$, R. König', M. Kubkowska ${ }^{3}$, O. Marchuk², \\ N. Pablant ${ }^{4}$, L. Ryc ${ }^{3}$, T.S. Pedersen ${ }^{1}$ and the W7-X team ${ }^{1}$ \\ ${ }^{1}$ Max-Planck-Institut für Plasmaphysik, 17491 Greifswald, Germany \\ ${ }^{2}$ Forschungszentrum Jülich GmbH, Institut für Energie- und Klimaforschung \\ - Plasmaphysik, 52425 Jülich, Germany \\ ${ }^{3}$ Institute of Plasma Physics and Laser Microfusion (IPPLM), Poland \\ ${ }^{4}$ Princeton Plasma Physics Laboratory, Princeton, NJ, USA
}

\begin{abstract}
An essential element for stationary stellarator operation is the understanding of the impurity transport behavior. Neoclassical theory predicts an impurity transport towards the plasma core for the standard ion root regime in stellarators [1,2]. The performance of a quasistationary device like Wendelstein 7-X stellarator (W7-X, presently in the commissioning phase in Greifswald, Germany) could be limited in case of strong impurity accumulation. Therefore, a set of plasma diagnostics is foreseen to obtain key experimental quantities for the neoclassical transport modeling as ion temperature profile, density gradients and impurity concentration [3]. The core impurity content is monitored by the High Efficiency eXtreme ultraviolet Overview Spectrometer system (HEXOS) [4], covering the wavelength range 2.5-160 nm (intermediate ionization states of all relevant heavy intrinsic impurity species) with high spectral resolution and a time resolution of $1 \mathrm{~ms}$, adequate for transport analysis. Impurity radiation at shorter wave lengths ( $4 \mathrm{~nm}-0.06 \mathrm{~nm}$ ) will be monitored with the SX pulse height analysis system (PHA) [5]. The ion temperature profile can be deduced from inversion of data from the High Resolution Xray Imaging Spectrometer (HR-XIS), which measures the concentration and temperature of argon tracer gas in helium-like ionization stages [6-8]. A second X-ray Imaging Crystal Spectrometer (XICS), which will additionally provide the poloidal ion rotation velocity, is under preparation [8,9]. The total radiation will be measured by two bolometer cameras [10,11]. The status of the impurity diagnostics for the first operational phase in $\mathrm{W} 7-\mathrm{X}$ is summarized in this paper and an outlook for the next experimental campaign is given.
\end{abstract}

The paper is published by JINST

First EPs Conference on Plasma Diagnostics - $1^{\text {st }}$ ECPD

14-17 April 2015,

Villa Mondragone, Frascati (Rome) Italy

* Speaker 